Matrik : Jurnal Manajemen, Teknik Informatika, dan Rekayasa Komputer

Vol. 20, No. 1, November 2020, pp. 27 34

ISSN: $2476-9843$, accredited by Kemenristekdikti, Decree No: 3/E/KPT/2019

\title{
Deteksi Citra Bunga Menggunakan Analisis Segmentasi Fuzzy C-Means dan Otsu Threshold
}

Perani Rosyani, Saprudin

Universitas Pamulang, Indonesia

\begin{tabular}{l} 
Informasi Artikel \\
\hline Article history: \\
Received, 25 April 2020 \\
Revised, 2 May 2020 \\
Accepted, 2 July 2020 \\
\hline
\end{tabular}

\section{Kata kunci:}

Deteksi

Segmentasi

Fuzzy C-Means

Otsu Threshold

Citra Bunga

Keywords:
Detection
Segmentation
Fuzzy C-Means
Otsu Threshold
Flower Image

\section{Penulis Korespondensi:}

Perani Rosyani,

Program Studi Teknik Informatika, Universitas Pamulang.

Email: dosen00837@unpam.ac.id

\begin{abstract}
ABSTRAK
Segmentasi merupakan proses penting di dalam proses pengenalan citra. Segmentasi citra penting untuk mengektrasi fitur yang kita akan ambil sebagai data di dalam penelitian. Beberapa metode segmentasi digunakan di dalam proses pengambilan fitur. Namun di dalam penelitian ini kami menggunakan metode Fuzzy C-Means dan Otsu Threshold untuk mendeteksi citra bunga. Agar citra bunga dapat dikenali oleh komputer seperti penglihatan manusia. Dataset yang digunakan mengunakan Imageclef 2017. Citra yang diambil sebagai sample sebanyak 41 citra dengan kondisi background citra yang komplek dengan noise. Tujuan penelitian ini adalah mendapatkan metode segmentasi yang lebih baik di antara metode Fuzzy C-Means dengan Otsu Threshold. Hasil dari penelitian ini didapat dari 41 percobaan keberhasilan segmentasi Fuzzy $C$ Means mendeteksi objek secara sempurna adalah sebanyak 28 citra dan 16 citra yang gagal. Sedangkan untuk segmentasi menggunakan Otsu Threshold adalah sebanyak 24 citra yang sesuai dan 17 citra yang gagal. Persentase keberhasilan untuk metode Fuzzy C-Means adalah $61 \%$ dan untuk metode Otsu Threshold 70,8\%.
\end{abstract}

\section{ABSTRACT}

Segmentation is an important process in the process of image recognition. Image segmentation is important for extracting features that we will take as data in research. Several segmentation methods are used in the feature capture process. But in this study we use the Fuzzy C-Means and Otsu Threshold methods to detect flower images. So that the flower image can be recognized by a computer like human vision. The dataset used is Imageclef 2017. The images taken as a sample are 41 images with background conditions that are complex with noise. The purpose of this study is to get a better segmentation method between the Fuzzy C-Means method and Otsu Threshold. The results of this study obtained from 41 successful experiments on Fuzzy C-Means segmentation to detect objects perfectly were 28 images and 16 failed images. Whereas for segmentation using Otsu Threshold there are 24 matching images and 17 failed images. The percentage of success for the Fuzzy C-Means method is $61 \%$ and for the Otsu Threshold method 70.8\%.

This is an open access article under the CC BY-SA license.

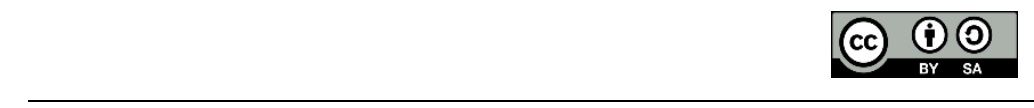




\section{PENDAHULUAN}

Deteksi di dalam pengenalan objek pada citra telah banyak dikembangkan melalui fitur warna, bentuk, dan tekstur untuk dapat dikenali sebagai sebuah objek [1]. Untuk mendapatkan fitur-fitur yang dapat diproses untuk mengenali sebuah objek dibutuhkan sebuah proses segmentasi. Segmentasi merupakan bagian dari pengolahan citra digital dan merupakan proses yang cukup penting [2] [ [ $\underline{3}$. Segmentasi citra ini sudah banyak digunakan salah satunya untuk citra MRI [4], pengenalan plat kendaraan bermotor [ $\underline{5}$, pengenalan wajah [6] dan pengenalan citra bunga [7] .

Banyak metode segmentasi yang diterapkan untuk mendapatkan fitur-fitur yang baik di dalam deteksi objek, salah satunya Otsu Threshold. Metode ini membuat citra warna menjadi citra biner atau citra keabuan [8]. Metode Otsu ini memiliki kelebihan di dalam komputasi yang ringan dan proses yang cepat [9], [10].

Di dalam penelitian ini penulis mengimplementasikan segmentasi citra menggunakan Otsu thresholding untuk mendapatkan hasil deteksi yang baik pada citra bunga. Penelitian ini juga membandingkan metode segmentasi Otsu Threshold dengan Fuzzy C-Means untuk mendapatkan hasil terbaik dari perbandingan kedua metode tersebut. Segmentasi Fuzzy C-Means memiliki kelebihan di dalam pengolahan background citra yang kompleks [11].

Penelitian ini menggunakan 20 jenis citra RGB untuk proses segmentasi menggunakan Otsu Threshold dan Fuzzy C-Means dengan pendekatan warna LAB. Model warna LAB ini dibuat serupa dengan persepsi penglihatan manusia dengan mengimplementasikan tiga komponen yaitu L sebagai luminance lalu A dan B sebagai dimensi warna yang berlawanan [12]. Citra yang digunakan di dalam penelitian ini merupakan citra dengan latar belakang yang cukup kompleks ada daun dan ranting pohon, maka diperlukan proses segmentasi yang baik untuk menghilangkan noise yang ada.

Penelitian ini menggabungkan proses canny edge sebagai proses deteksi objek. Canny edge digunakan untuk memeriksa dan menghapus noise-noise yang ada [13], sehingga meningkatkan tingkat akurasi di dalam pengenalan objek. Karena canny edge memiliki tingkat kehalusan dan pendeteksi tepi ke dalam suatu konvolusi dalam satu dimensi dengan dua arah yang berbeda (vertical dan horizontal) [14]. Tujuan penelitian ini adalah untuk memisahkan objek bunga dengan menggunakan segmentasi Otsu Threshold dan Fuzzy C-Means. Dengan menggunakan metode ini diharapkan dapat mempermudah proses pengenalan citra bunga.

\section{METODE PENELITIAN}

Jenis penelitian yang digunakan adalah penelitian kualitatif di mana penelitian yang dilakukan dengan mengembangkan model matematika, teori atau hipotesis. Berikut adalah metode penelitian yang diusulkan sebagai berikut:

1. Pemilihan Citra

Pada tahapan ini penulis memilih sample bunga yang ingin di proses dengan kondisi citra background yang kompleks berlatar hijau.

2. Konversi Citra

Konversi citra di dalam penelitian ini untuk mempermudah operasi-operasi selanjutnya berjalan dengan baik. Untuk metode Otsu Threshold menggunakan konversi warna RGB menjadi grayscale, sedangkan untuk Fuzzy C-Means mengkonversi citra warna RGB menjadi LAB.

3. Segmentasi

Segmentasi citra di dalam penelitian ini bertujuan untuk memisahkan antara background dengan objek yang diinginkan.

4. Pembersihan Noise

Operator-operator untuk membersihkan noise ini berbeda untuk setiap metode Otsu Threshold dan Fuzzy C-Means. Karena membutuhkan operator yang ber-beda untuk meningkatkan nilai akurasi. 
5. Deteksi Objek

Deteksi objek menggunakan operator deteksi tepi canny untuk mendeteksi jumlah objek yang didapat setelah background dibersihkan.

6. Menilai Akurasi

Ini merupakan tahapan pengambilan kesimpulan untuk kedua metode tersebut. Mana yang lebih baik diantara metode Otsu Threshold dengan Fuzzy C-Means.

Untuk memperjelas langkah-langkah di atas dapat dilihat dari alur penelitian pada gambar 1.

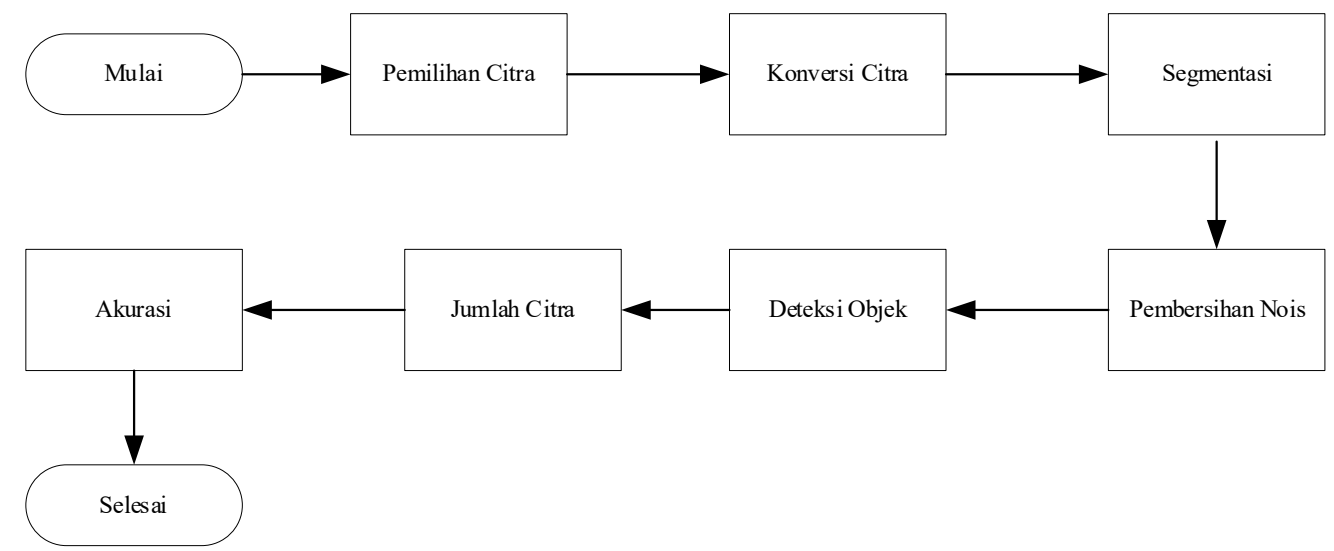

Gambar 1. Alur Penelitian

Setelah dataset dikumpulkan, maka akan diproses dengan menggunakan segmentasi Otsu Threshold dan Fuzzy C-Means. Setelah selesai akan dicoba dan ditarik kesimpulan serta saran akan diambil dari hasil percobaan. Dataset yang terdiri dari 10.000 gambar berasal dari ImageClef 2017. Sample yang digunakan di dalam penelitian ini terdiri dari 20 citra bunga dengan background yang kompleks. Gambar 2 merupakan sample yang diambil untuk pengujian. Kita bisa lihat background yang diambil cukup kompleks sehingga dibutuhkan beberapa operasi untuk menghilangkan noise-noise tersebut.

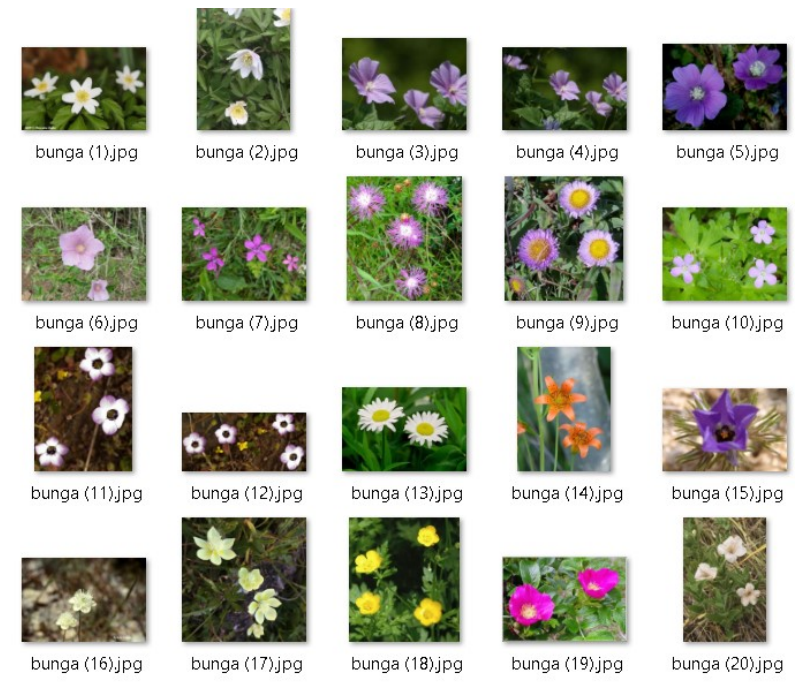

Gambar 2. Dataset citra bunga dari ImageClef 2017

Deteksi tepi berfungsi untuk memperoleh batasan dari suatu citra pada gambar 3. Deteksi tepi di dalam penelitian ini menggunakan canny edge karena dapat mendeteksi dengan baik [15]. Karena memiliki kemampuan untuk meletakkan dan menandai semua tepi yang ada sesuai dengan pemilihan parameter-parameter konvolusi yang dilakukan ke dalam metode Otsu Threshold dan Fuzzy C-Means untuk dipisahkan objeknya, sehingga dapat dikenali sebagai citra bunga di dalam komputer. 


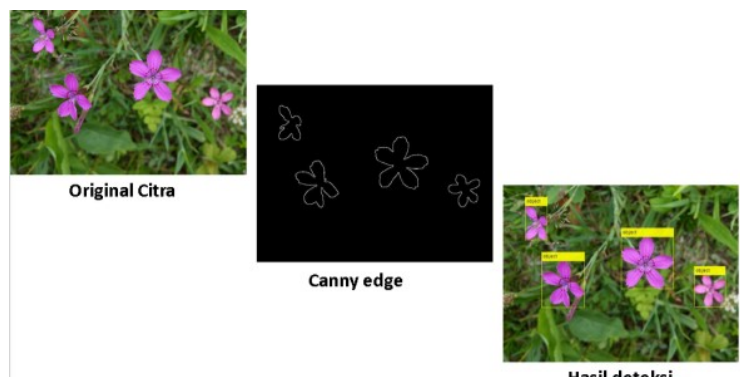

Gambar 3. Proses Canny Edge

Proses deteksi objek ini akan diawali dengan konversi warna grayscale terlebih dahulu untuk metode Otsu Threshold yang kami terapkan di dalam penelitian ini. Setelah itu citra gray dibuat menjadi citra biner agar resolusi yang dihasilkan lebih ringan. Dan baru dilakukan segmentasi menggunakan fungsi Otsu Threshold. Dengan penambahan operasi filter, holes, closing, erosi dan deteksi canny edge. Sehingga dihasilkan citra tanpa background. Kemudian dideteksi untuk dikenali sebagai objek bunga.

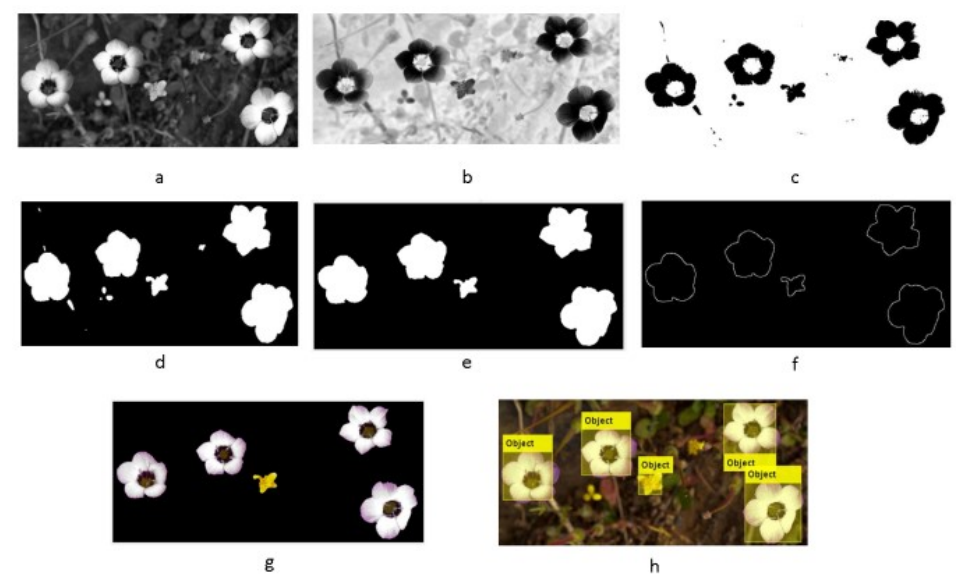

Gambar 4. Proses Otsu Treshold

Jika dilihat dari gambar 4 a) citra gray, b) citra incomplement, c) citra biner, d) closing dan erosi, e) bware open, f) deteksi canny, g) pemisahan objek dengan background, h) objek dikenali. Dari proses Otsu di atas kita bisa lihat jumlah objek bunga di awal berjumlah 5 dan dari hasil segmentasi Otsu Threshold dapat dideteksi objek bunga tersebut juga dengan jumlah 5. Gambaran langkah-langkah proses dari Otsu Threshold di dalam penelitian ini secara visual dapat dilihat pada gambar 5.

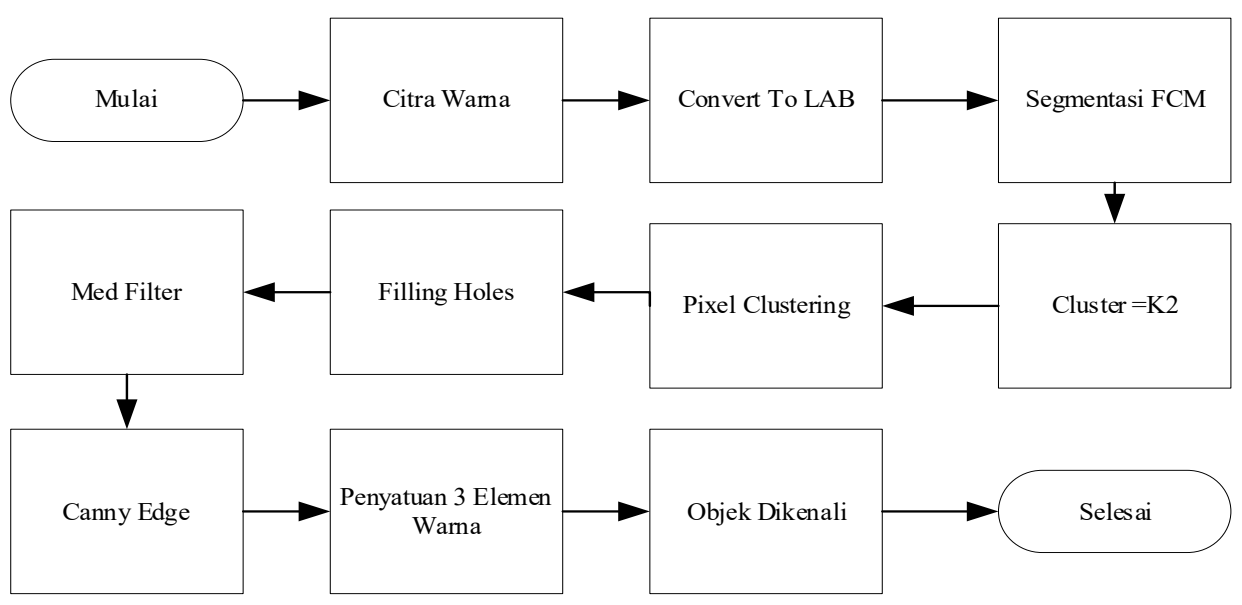

Gambar 5. Flowchart Otsu Threshold 
Dalam proses segmentasi menggunakan Fuzzy C-Means citra warna akan dikonversi ke citra LAB. Menurut literatur [16], citra lab merupakan ruang warna yang cocok untuk proses deteksi pada objek.. Maka di dalam penelitian ini kami mengkonversi warna RGB menjadi LAB yang kemudian disegmentasi menggunakan Fuzzy C-Means. Dengan $\mathrm{K}=2$. Fuzzy C-Means merupakan suatu Teknik clustering (pengelompokan) data dimana keberadaan titik-titik data di dalam cluster ditentukan oleh derajat keanggotaan [11]. Langkah-langkah segmentasi menggunakan Fuzzy C-Means (FCM) dapat kita lihat pada gambar 5.

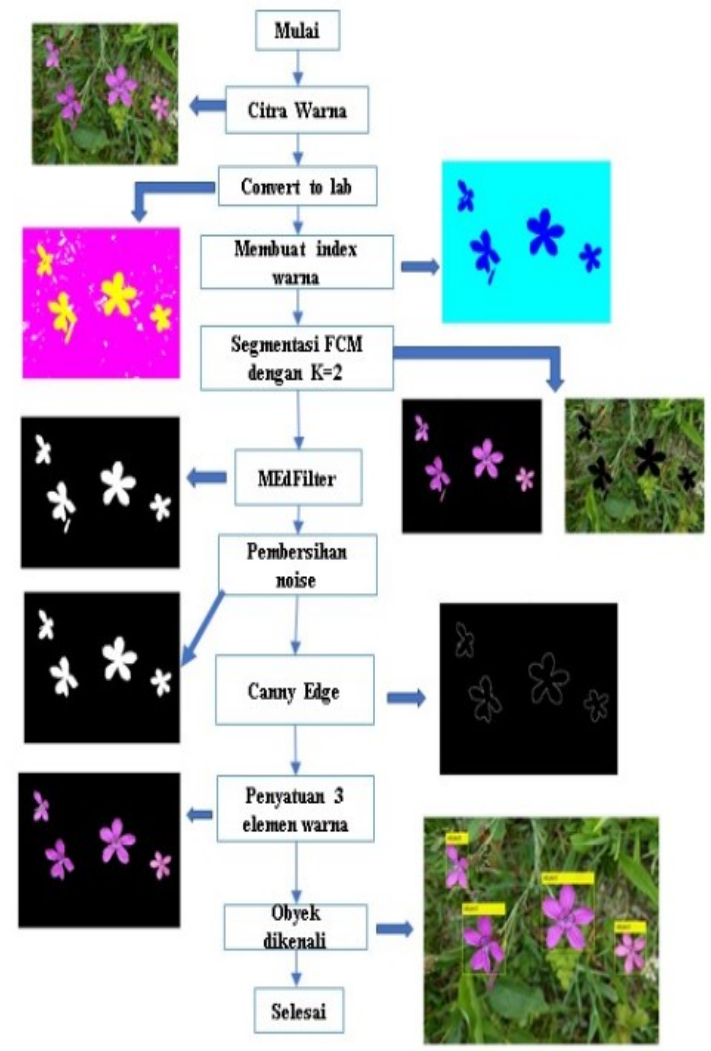

Gambar 6. Alur Fuzzy C-Means

Berdasarkan alur gambar 5, kita bisa melihat citra awal dengan hasil objek yang dideteksi. Citra awal memiliki jumlah 4 bunga dan dengan menggunakan segmentasi FCM untuk mengekstrak fitur dari citra bunga tersebut dan di bantu dengan operasi-operasi pengolahan citra yang lain, maka hasil objek yang dihasilkan sesuai dengan jumlah objek bunga yang ada.

\section{HASIL DAN ANALISIS}

Percobaan dilakukan pada 20 citra bunga, dimana hasil yang diperoleh setelah melakukan penelitian adalah disajikan pada Tabel 1 . 
Tabel 1. Perbandingan jumlah objek yang terdeteksi dari metode Otsu Threshold dan FCM

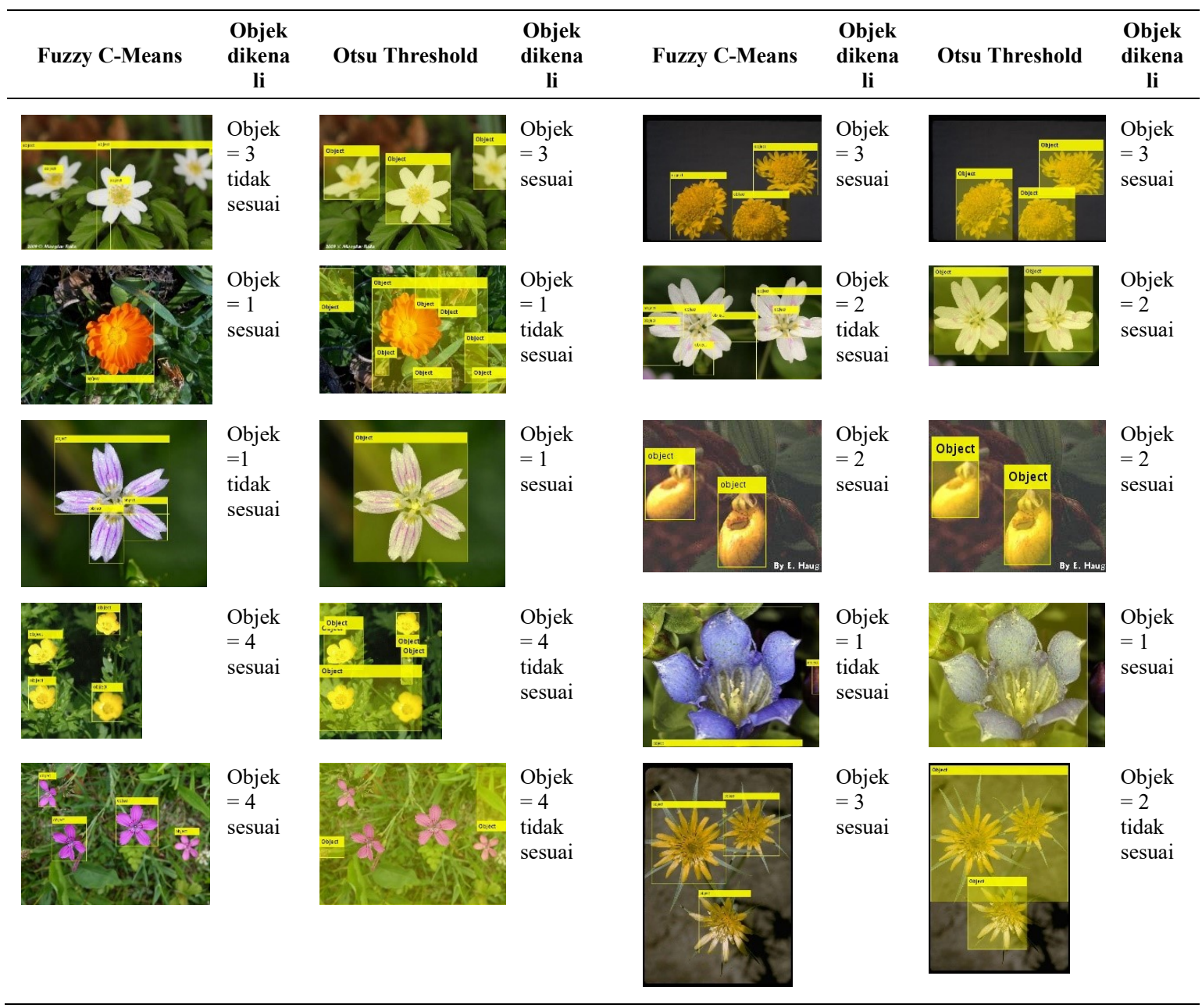

Berdasarkan Tabel 1 maka kami mencoba merekap hasil deteksi yang sesuai dengan jumlah objek dan yang tidak. Tabel 1 menggunakan 41 sample gambar dengan latar belakang yang kompleks, sehingga didapatkan angka kesesuaian jumlah objek pada Tabel 2.

Tabel 2. Jumlah Kesesuaian Objek

\begin{tabular}{llc}
\hline \multicolumn{1}{c}{ Deteksi } & FCM & Otsu Threshold \\
\hline Sesuai & 25 & 24 \\
Tidak Sesuai & 16 & 17 \\
\hline
\end{tabular}

Pada keseluruhan percobaan untuk deteksi objek berhasil mengenali 100\% adalah sebanyak 25 citra yang sesuai dideteksi baik menggunakan segmentsi FCM maupun Otsu Threshold atau sekitar 61\% berhasil dideteksi dan dikenali sesuai dengan objek yang dapat dikenali oleh manusia. Sedangkan terdapat 9 citra atau sekitar $21 \%$ citra yang dapat dideteksi dengan baik dan berjumlah sesuai dengan kedua metode tersebut.

Dimana ada kegagalan yang terjadi pada beberapa citra karena kegagalan di dalam proses segmentasi. Sehingga citra tersebut tidak bisa dideteksi dan dikenali, baik menggunakan metode Otsu Threshold maupun Fuzzy C-Means. 
Tabel 3. Ketidaksesuain Citra pada Kedua Metode

\begin{tabular}{llrl}
\hline Fuzzy C-Means & Objek dikenali & Otsu Threshold & Objek dikenali \\
\hline & Objek $=4$ tidak sesuai & Objek $=4$ tidak sesuai \\
\hline & & & \\
\hline & & & Objek $=2$ tidak sesuai \\
\hline & & & \\
\hline
\end{tabular}

Pada Tabel 3 hasil segmentasi untuk mendeteksi objek sangat jauh. Objek bunga yang seharusnya hanya berjumlah 4, dengan metode FCM terdeteksi 5 bunga. Sedangkan untuk Otsu Threshold berjumlah 2. Bentuk dari objek bunga cukup mempengaruhi proses segmentasi citra ini.

\section{KESIMPULAN}

Setelah melakukan analisa hasil pada deteksi objek bunga dengan menggunakan segmentasi Fuzzy C-Means dan Otsu Threshold dapat diambil kesimpulan bahwa dari 41 percobaan keberhasilan segmentasi Fuzzy C-Means mendeteksi objek secara sempurna adalah sebanyak 28 citra dan 16 citra yang gagal. Sedangkan untuk segmentasi menggunakan Otsu Threshold adalah sebanyak 24 citra yang sesuai dan 17 citra yang gagal. Terdapat 9 citra yang dapat dideteksi oleh metode Fuzzy C-Means dan Otsu Threshold dengan tepat. Persentase keberhasilan untuk metode Fuzzy C-Means adalah $61 \%$ dan untuk metode Otsu Threshold 70,8\%.

\section{UCAPAN TERIMA KASIH}

Kami ingin mengucapakan terima kasih kepada Prodi Teknik Informatika dan Lembaga Penelitian Pengabdian Masyarakat Universitas Pamulang yang telah mendukung kami.

\section{REFERENSI}

[1] I. A. Sulistyo, "Sistem Deteksi Panen Padi Berdasarkan Warna Daun Menggunakan Fuzzy C-Means," 2017.

[2] S. Wulansari, "Segmentasi Citra Berwarna Menggunakan Deteksi Tepi dan Fuzzy C-Means yang Dimodifikasi Berdasarkan Informasi Ketetanggaan,” Institut Teknologi Sepuluh Nopember, 2015.

[3] D. H. Apriyanti, A. M. Arymurthy, and L. T. Handoko, "Identification of Orchid Species using Content-based Flower Image Retrieval," in International Conference on Computer, Control, Informatics and Its Applications (IC3INA), 2013, pp. 53-57.

[4] E. Varijki and B. K. Triwijoyo, "Segmentasi Citra MRI Menggunakan Deteksi Tepi Untuk Identifikasi Kanker Payudara," MATRIK : Jurnal Manajemen, Teknik Informatika dan Rekayasa Komputer, vol. 15, no. 2, p. 17, Jul. 2017.

[5] M. Michael, F. Tanoto, E. Wibowo, F. Lutan, and A. Dharma, "Pengenalan Plat Kendaraan Bermotor dengan Menggunakan Metode Template Matching dan Deep Belief Network," MATRIK: Jurnal Manajemen, Teknik Informatika dan Rekayasa Komputer, vol. 19, no. 1, pp. 27-36, Nov. 2019.

[6] P. Rosyani, "Pengenalan Wajah Menggunakan Metode Principal Component Analysis (PCA) dan Canberra Distance," Jurnal Informatika Universitas Pamulang, vol. 2, no. 2, p. 118, 2017.

[7] P. Rosyani, M. Taufik, A. A. Waskita, and D. H. Apriyanti, "Comparison of Color Model for Flower Recognition," in International Conference on Information Technology, Information System and Electrical Engineering (ICITISEE), 2018, pp. 10-14.

[8] G. B. Adhi and I. D. Wahyono, "Segmentasi Gambar Warna Menggunakan Sauvola Modifikasi Fuzzy C-Means (SMFCM)," Lontar Komputer : Jurnal Ilmiah Teknologi Informasi, vol. 5, no. 2, pp. 416423, 2015.

[9] A. Ambarwati, R. Passarella, and Sutarno, "Segmentasi Citra Digital Menggunakan Thresholding Otsu 
untuk Analisa Perbandingan Deteksi Tepi,” in Annual Research Seminar, 2016, vol. 2, no. 1, pp. 216 226.

[10] H. D. Cheng, X. H. Jiang, Y. Sun, and J. Wang, "Color Image Segmentation: Advances and Prospects," Pattern Recognition, vol. 34, no. 12, pp. 2259-2281, 2001.

[11] I. S. Wibisono and S. Mujiyono, "Segmentasi Fuzzy C-Means Untuk Membantu Identifikasi Kualitas Beras Berdasarkan Nilai Threshold, Warna Dan Ukuran," Multimatrix : Jurnal Ilmu Komputer, vol. 1, no. 1, pp. 22-25, 2018.

[12] Y. A. Enggarwati, Ani Sari and R. C. Wihandika, "Segmentasi Citra Kue Tradisional menggunakan Ruang Warna Hue Saturation Segmentasi Citra Kue Tradisional menggunakan Ruang Warna Hue Saturation Value dan Otsu Thresholding," JPTIIK (Jurnal Pengembangan Teknologi Informasi dan Ilmu Komputer), vol. 3, no. 8, pp. 7556-7560, 2019.

[13] P. Selvakumar and S. H. Ganesh, "Tamil Character Recognition Using Canny Edge Detection Algorithm," in World Congress on Computing and Communication Technologies (WCCCT), 2017, pp. 250-254.

[14] D. Anggraeni P, V. A. Putri, S. F. Al-Uswah, M. F. H. Tulloh, and M. S. Zuhri, "Segementasi Citra Digital Ikan Menggunakan Metode Thresholding dan K-Means," Yudistira Lecture, vol. 1, no. 1, pp. $1-10,2014$.

[15] P. Bao, Lei Zhang, and Xiaolin Wu, "Canny Edge Detection Enhancement by Scale Multiplication," IEEE Transactions on Pattern Analysis and Machine Intelligence, vol. 27, no. 9, pp. 1485-1490, Sep. 2005.

[16] S. Marimuthu and S. M. M. Roomi, "Particle Swarm Optimized Fuzzy Model for the Classification of Banana Ripeness," IEEE Sensors Journal, vol. 17, no. 15, pp. 4903-4915, 2017. 